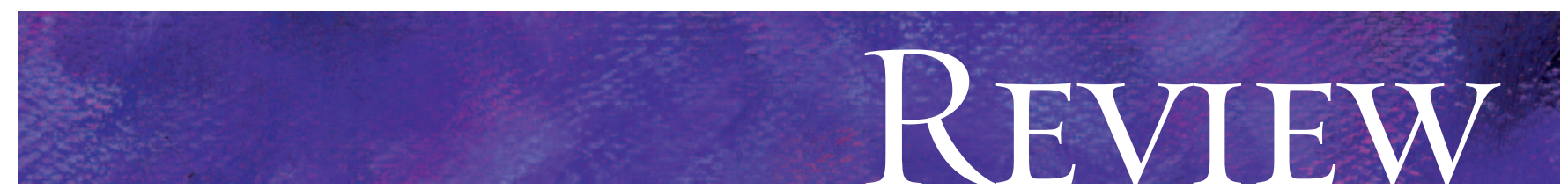

\title{
The cost-effectiveness of drug-eluting stents: a systematic review
}

\section{Suzanne Ligthart, Floortje Vlemmix, Nandini Dendukuri, James M. Brophy}

Published at www.cmaj.ca on Dec. I9, 2006. Revised on Dec. 28, 2006.

$\infty \quad$ See related articles, pages I95 and I99

\section{ABSTRACT}

Background: Drug-eluting stents have been seen as an attractive alternative to bare-metal stents for percutaneous coronary interventions ( $\mathrm{PCls}$ ) because of the decreased need for revascularization. However, comparative clinical trials have shown no difference in patient outcomes, and drug-eluting stents are considerably more expensive than their bare-metal counterparts. We conducted a systematic review of all published comparative cost-effectiveness analyses to identify the factors contributing to the heterogeneity of their conclusions.

Methods: We retrieved all articles published between Jan. 1, 2000, and July 31, 2006, in which the cost-effectiveness, from a third-party payer perspective, of drug-eluting stents was compared with that of bare-metal stents for $\mathrm{PCl}$ in unrestricted patient populations. Electronic databases, Web sites from health technology assessment groups and references of identified articles were searched. Our outcome variable was whether the study's conclusions favoured widespread use of drug-eluting stents, as assessed by 4 independent reviewers. Study characteristics such as quality, funding source, country and year of publication were extracted. Two-by-2 tables and Fisher's exact test were used to study the association between covariates and the outcome variable. A classification and regression tree (CART) model was used for multivariate analysis.

Results: We identified 19 cost-effectiveness analyses. Ten were in favour of widespread use of drug-eluting stents, and 9 favoured more restrained use. Only 1 of 9 high-quality studies supported widespread use, as compared with 9 of 10 lower quality studies $(p<0.001)$. All of the 7 sponsored studies argued in favour of widespread use, as compared with 3 of the 12 studies without sponsorship $(p=0.003)$. Studies from the United States were more likely than those from other countries to endorse unlimited use $(p=0.032)$. A CART model with 2 covariates - study quality and sponsorship - provided the best fit (error rate 10.5\%).

Interpretation: Conclusions drawn by cost-effectiveness analyses of drug-eluting stents for $\mathrm{PCl}$ are associated with the study's quality, funding source and country of origin. Vigilance regarding these study characteristics is required when interpreting findings from cost-effectiveness analyses.

CMAJ 2007;176(2):199-205
$\mathrm{D}$ rug-eluting stents became commercially available in 2002 in Europe and Canada and in 2003 in the United States ${ }^{1}$ and are now widely used in the treatment of coronary artery disease. Restenosis of the target lesion has been the "Achilles heel" of percutaneous coronary interventions (PCIs), with $15 \%-40 \%$ of patients in randomized controlled trials (RCTs) who received bare-metal stents needing repeat revascularization within 6 months. ${ }^{2}$ Numerous $\mathrm{RCTs}^{3-6}$ and meta-analyses ${ }^{7}$ have shown that the use of drug-eluting stents reduces this risk by an estimated $83 \%$. Given their comparable short-term safety profiles, drugeluting stents have been seen as an attractive clinical alternative to bare-metal stents. However, no differences in deaths or myocardial infarctions have been seen between study groups receiving either type of stent. ${ }^{7}$ Furthermore, the absolute reductions in the rate of repeat revascularization observed with drug-eluting stents may be overestimated, owing to protocoldriven angiographic follow-up in RCTs. ${ }^{8,9}$ Nevertheless, the clinical benefits of fewer repeat revascularizations with drugeluting stents and improved quality of life, even if ephemeral, are enticing.

Because drug-eluting stents are considerably more expensive than bare-metal stents, with an estimated world market of $\$ 6$ billion annually, ${ }^{10}$ cost-effectiveness analyses may help decision-makers assess the value of this additional investment. Although many cost-effectiveness studies have been carried out, they have arrived at different conclusions despite using a relatively constant measure of the efficacy of drugeluting stents. By systematically reviewing all published costeffectiveness analyses, we attempt to understand the determinants of the different conclusions.

\section{Methods}

We performed an extensive literature search for all Englishlanguage cost-effectiveness studies published between Jan. I, 2000 , and July 3I, 2006, that assessed the impact of costs of drug-eluting stents compared with bare-metal stents on a health care system. We decided not to distinguish between the different models of drug-eluting stents because, although sirolimus-eluting stents appear to be more clinically effective than paclitaxel-eluting ones, ${ }^{11}$ both are extensively used in clinical practice and because the prices of drug-eluting stents 
are comparable. Electronic search terms were "stent" and ("sirolimus" or "rapamycin" or "paclitaxel" or "taxus" or "cypher" or "drug eluting"] and ["economic(s)" or "cost(s)"]. We searched MEDLINE, EMBASE and the Cochrane Library as well as the HTA, DARE and NHS EED databases (www.york.ac .uk/inst/crd/crddatabases.htm). In addition, we reviewed 40 Web sites from known health technology assessment agencies in 2I countries (www.inahta.org) and references from identified articles. Studies were first identified based on their title and abstract and subsequently were retained if they met the following inclusion criteria: they were written from a thirdparty payer perspective; they used bare-metal stents as the comparator in their cost analyses; and they provided an original cost-effectiveness analysis from an unrestricted patient population.

For each study, geographic location, study quality, year of publication, funding source and overall conclusions were extracted. Because a minority of studies reported findings in the standard economic metric of cost per quality-adjusted lifeyear (QALY) and because we wished to simplify the interpretation of our results, the conclusion of each study was dichotomized as favourable or not favourable toward the widespread use of drug-eluting stents as an alternative to bare-metal stents. To strengthen the reliability of our assessment, this outcome variable was coded by 4 independent reviewers, 2 of whom were blinded to the studies' authors, their affiliations and funding sources. There was perfect initial agreement among the 4 reviewers on $\mathrm{I}_{5}$ of the $\mathrm{I} 9$ articles included in the analysis. Differences were discussed for the remaining 4 until universal agreement was reached.

To determine the quality of each study, we used a structured data-collection form created on the basis of previous published guidelines and recommendations (see Appendix I, available online at www.cmaj.ca/cgi/content/full/176/2/199 /DCI). ${ }^{12}$ Each of the 16 items in this instrument were accorded I point if present, and a total quality score was obtained by summing across the items. Thus, the scale varied from o to 16 , with higher values indicating better quality. Quality parameters were extracted and assessed independently by 2 of us (S.L. and F.V.) and discrepancies resolved by consensus.

Studies assigned a score above the median (Io points) were classified as high quality and the remaining as low quality. The measurement of quality is thus a relative measurement and gives information about the quality of one study compared with that of the other cost-effectiveness analyses. However, it does not provide information on the validity and appropriateness of the data used in the analyses. To evaluate the validity of this instrument, we performed a sensitivity analysis using the previously validated Quality of Health Economic Studies (QHES) instrument (see Appendix 2, available online at www.cmaj.ca/cgi/content/full/I76/2/I99/DCI) ${ }^{13,14}$ which includes measures of the quality of the different input variables but is therefore also potentially more sensitive to

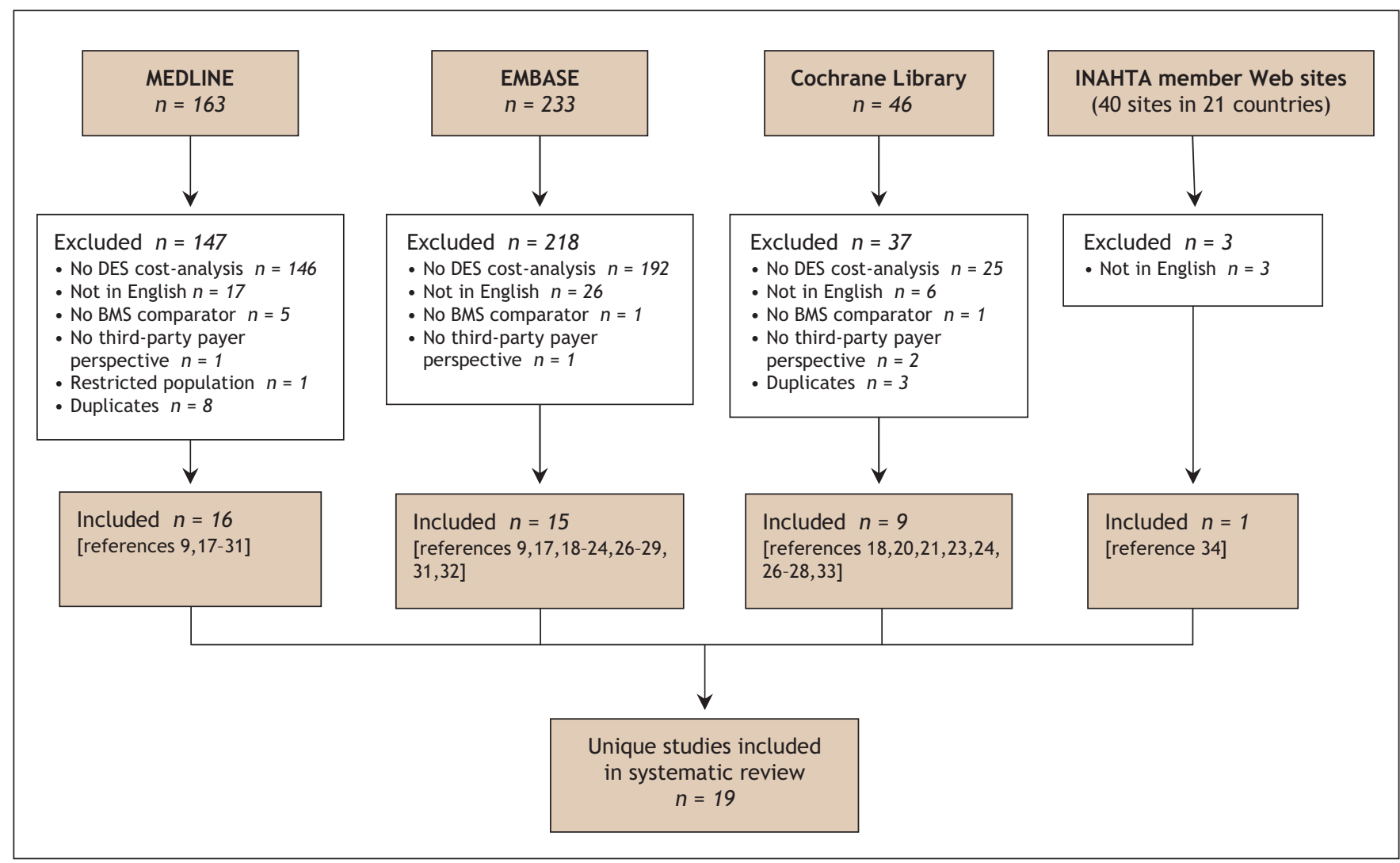

Fig. 1: Results of literature search for cost-effectiveness analyses comparing drug-eluting stents (DES) and bare-metal stents (BMS). See Methods for search terms. INAHTA = International Network of Agencies for Health Technology Assessment (www.inahta.org). 
subjectivity. Scores on the QHES scale vary from o to Ioo, with higher scores indicating better quality. Using the median of this scale (62), we again dichotomized studies as being of high quality or low quality, and any disagreements between the 2 extractors were settled by consensus.

Studies were considered to be sponsored if the original publications indicated that funding was provided directly by the manufacturer of a drug-eluting stent.

For statistical analysis, we used $2 \times 2$ tables to study the association between categorical covariates, and between each covariate and the main outcome measure. Fisher's exact test was used to examine the strength of the associations. We conducted a multivariable analysis, relating the outcome measure to all covariates, using a classification and regression tree (CART) model. ${ }^{15,16}$ CART models are fit with the use of nonparametric statistical methods suitable for small data sets. At each stage of the CART model, the sample is split into 2 groups (or nodes) based on a single covariate that is associated with the greatest variability in the outcome measure. The classification process ends when there are 5 or fewer observations in a node.

\section{Results}

We identified I9 eligible studies published between Jan. I, 2000, and July 3I, 2006 (Fig. I). The majority were found through our search of MEDLINE and EMBASE, ${ }^{9,17-32}$ with an additional study each identified from the Cochrane Library ${ }^{33}$ and the Web sites of known health technology assessment agencies. ${ }^{34}$ When available, additional information referenced in the original publication was considered to permit a more thorough assessment of study quality.

The characteristics of the studies and whether they favoured widespread use of drug-eluting stents are presented in Table I. Ten of the I9 studies were classified as being in favour of widespread use. Our main outcome measure was associated with a threshold of $\$ 50$ ooo per QALY in the 9 studies that reported this metric: both of the studies that reported a cost of less than $\$ 50$ ooo per QALY were in favour of widespread use, as compared with I of 7 studies that reported a cost of more than $\$ 50$ ooo per QALY (88.9\% accuracy, $p=0.083$ ). Exerpts from the original publications supporting our dichotomous classification are provided in Table 2.

One of the 9 studies with a quality score above the median supported widespread use of drug-eluting stents (Table 3), in contrast to 9 of the Io studies with a quality score below the median $(p<0.00 I)$. All of the 7 sponsored studies argued in favour of widespread use of drug-eluting stents, in contrast to 3 of the 12 studies without direct sponsorship $(p=0.003)$. All of the 5 studies that performed a cost-effectiveness analysis from a US cost perspective concluded that drug-eluting stents were a favourable economic intervention,

Table 1: Main characteristics of studies included in the systematic review of published cost-effectiveness analyses comparing drugeluting and bare-metal stents

\begin{tabular}{|c|c|c|c|c|c|c|c|}
\hline Study & $\begin{array}{c}\text { Year of } \\
\text { publication }\end{array}$ & $\begin{array}{l}\text { Quality* } \\
\text { (score) }\end{array}$ & $\begin{array}{l}\text { QHES† } \\
\text { (score) }\end{array}$ & Sponsored‡ & Country & $\begin{array}{c}\text { ICER }>\$ 50000 \\
\text { per QALY }\end{array}$ & $\begin{array}{l}\text { Conclusions favoured } \\
\text { widespread use of } \\
\text { drug-eluting stents }\end{array}$ \\
\hline Greenberg et $\mathrm{al}^{17}$ & 2002 & $0 \quad(9)$ & $0(22)$ & No & United States & NA & Yes \\
\hline Galanaud et al ${ }^{18}$ & 2003 & $0 \quad(9)$ & $0(42)$ & No & France & NA & Yes \\
\hline Ruffy et $\mathrm{al}^{32}$ & 2003 & $0 \quad(3)$ & $0(18)$ & Yes & United States & NA & Yes \\
\hline Greenberg et al $^{19}$ & 2004 & $0 \quad(7)$ & $0(48)$ & Yes & United States & NA & Yes \\
\hline Cohen et $\mathrm{al}^{20}$ & 2004 & $0(10)$ & $1(62)$ & Yes & United States & No & Yes \\
\hline Hill et $\mathrm{al}^{21}$ & 2004 & $1(15)$ & $1(85)$ & No & United Kingdom & Yes & No \\
\hline Tarricone et al $^{22}$ & 2004 & $0(10)$ & $0(47)$ & Yes & Italy & NA & Yes \\
\hline Brophy et $\mathrm{al}^{23}$ & 2004 & $1(16)$ & $1(92)$ & No & Canada & NA & No \\
\hline Ward et $\mathrm{al}^{9}$ & 2005 & $0 \quad(7)$ & $0(38)$ & No & Australia & NA & No \\
\hline Lord et $\mathrm{al}^{24}$ & 2005 & $1(13)$ & $0(55)$ & No & Australia & Yes & No \\
\hline Bagust et $\mathrm{al}^{25}$ & 2005 & $1(14)$ & $1(70)$ & No & United Kingdom & Yes & No \\
\hline Van Hout et $\mathrm{al}^{26}$ & 2005 & $0 \quad(8)$ & $0(50)$ & Yes & Netherlands & NA & Yes \\
\hline Shrive et $\mathrm{al}^{27}$ & 2005 & $1(13)$ & $1(94)$ & No & Canada & Yes & No \\
\hline Kaiser et $\mathrm{al}^{28}$ & 2005 & $1(14)$ & $1(62)$ & No & Germany & Yes & No \\
\hline Mittmann et al $^{33}$ & 2005 & $1(16)$ & $1(92)$ & No & Canada & NA & No \\
\hline Bowen et $\mathrm{al}^{34}$ & 2005 & $1(13)$ & $1(80)$ & No & Canada & Yes & No \\
\hline Bakhai et $\mathrm{al}^{29}$ & 2006 & $0(10)$ & $1(69)$ & Yes & United States & No & Yes \\
\hline Ekman et $\mathrm{al}^{30}$ & 2006 & $1(12)$ & $1(70)$ & Yes & Sweden & Yes & Yes \\
\hline Ikeda et $\mathrm{al}^{31}$ & 2006 & $0 \quad(7)$ & $0(44)$ & No & Japan & NA & Yes \\
\hline
\end{tabular}

Note: QHES = Quality of Health Economic Studies, ICER = incremental cost-effectiveness ratio, NA = not available.

${ }^{*}$ For quality, 1 = score was above median (i.e. high quality), $0=$ score was below median; median quality score $=10$.

†For QHES, 1 = score was above median on QHES instrument, 0 = score was below median on QHES instrument; median QHES score $=62$.

$\ddagger$ Directly sponsored by manufacturer of drug-eluting stent. 
as compared with 5 of the 14 studies performed outside the United States $(p=0.0325)$. Regarding year of publication, no clear time trend was observed, although a larger proportion of early (pre-2005) studies than of studies published in 2005 or later favoured widespread use $(75 \%$ [6/8] v. $36 \%$ [4/II], $p=0.17)$. One of the 8 studies published in 2005 reached a favourable conclusion $(p=0.04$ I compared with pre-2005 studies).

In the sensitivity analysis in which we used the QHES instrument to validate our quality assessment measure, 3 studies of intermediate quality ${ }^{24,28,29}$ changed categories, which resulted in our quality assessment measure having $80 \%$ sensi- tivity and $88.9 \%$ specificity with respect to the QHES instrument. When the QHES measure was compared with the outcome, 3 of ro higher quality and 7 of 9 lower quality studies were found to favour widespread use of drug-eluting stents $(p=0.07)$. Although not statistically significant, this finding supports the overall robustness both of our original quality scale and of the association between study quality and the outcome measure.

Although the CART model was fit using all variables, the final model comprised only 2 predictors of our outcome measure: lower study quality and direct sponsorship by a manufacturer of a drug-eluting stent (Fig. 2).

Table 2: Excerpts from the cost-effectiveness studies in support of the classification of whether their conclusions favoured widespread use of drug-eluting stents

\begin{tabular}{|c|c|c|}
\hline Study & Excerpt & $\begin{array}{l}\text { Conclusions favoured } \\
\text { widespread use of SES }\end{array}$ \\
\hline Greenberg et $\mathrm{al}^{17}$ & $\begin{array}{l}\text { "... cost saving for many patients and cost-effective for virtually all patients undergoing } \\
\mathrm{PCl}-\text { at least within the US healthcare system" }\end{array}$ & Yes \\
\hline Galanaud et $\mathrm{al}^{18}$ & $\begin{array}{l}\text { “... will provide additional value to society and might justify the price difference } \\
\text { between new and classical stents" }\end{array}$ & Yes \\
\hline Ruffy et $\mathrm{al}^{32}$ & "SES represent a promising cost-effective solution to this persistent complication" & Yes \\
\hline Greenberg et $\mathrm{al}^{19}$ & $\begin{array}{l}\text { "... that DES will be reasonably cost effective for the majority of patients and even cost } \\
\text { saving for a large subgroup of patients" }\end{array}$ & Yes \\
\hline Cohen et $\mathrm{al}^{20}$ & $\begin{array}{l}\text { "... their use appears to be reasonably cost-effective within the context of the US } \\
\text { healthcare system" }\end{array}$ & Yes \\
\hline Hill et $\mathrm{al}^{21}$ & "... so that DES would not normally be considered a cost-effective alternative" & No \\
\hline Tarricone et $\mathrm{al}^{22}$ & $\begin{array}{l}\text { "SES is thus a cost-saving strategy ...could therefore support the introduction of the new } \\
\text { technology" }\end{array}$ & Yes \\
\hline Brophy et $\mathrm{al}^{23}$ & $\begin{array}{l}\text { "Under current conditions in Quebec, Canada, selective use of DES in high-risk patients } \\
\text { is the most acceptable strategy in terms of cost-effectiveness" }\end{array}$ & No \\
\hline Ward et $\mathrm{al}^{9}$ & $\begin{array}{l}\text { "Current strategies for use of DES are not cost-effective. DES should be reserved for } \\
\text { restenosis until the price comes down" }\end{array}$ & No \\
\hline Lord et $\mathrm{al}^{24}$ & $\begin{array}{l}\text { "Decisions to limit DESs to only patients at the highest risk of restenosis may improve } \\
\text { their cost-effectiveness" }\end{array}$ & No \\
\hline Bagust et $\mathrm{al}^{25}$ & $\begin{array}{l}\text { "At current UK prices, drug-eluting stents are not cost-effective compared to } \\
\text { conventional stents except for a small minority of patients" }\end{array}$ & No \\
\hline Van Hout et $\mathrm{al}^{26}$ & "Suggest an attractive balance between costs and effects for sirolimus eluting stents" & Yes \\
\hline Shrive et $\mathrm{al}^{27}$ & $\begin{array}{l}\text { "The use of SES is associated with a cost per QALY that is similar to or higher than other } \\
\text { accepted medical forms of therapy and is associated with a significant incremental cost. } \\
\text { SES are more economically attractive for patients who are at higher risk of restenosis or } \\
\text { at high risk of death if a second revascularization procedure were to be required" }\end{array}$ & No \\
\hline Kaiser et $\mathrm{al}^{28}$ & $\begin{array}{l}\text { "DES in all patients is less cost effective than in studies with selected patients. Use of } \\
\text { these stents could be restricted to high-risk groups" }\end{array}$ & No \\
\hline Mittmann et $\mathrm{al}^{33}$ & $\begin{array}{l}\text { "Negotiating a lower DES acquisition cost or implementing criteria for the treatment of } \\
\text { high risk patients may make it more acceptable for hospitals and provinces to adopt DES } \\
\text { on a wider scale" }\end{array}$ & No \\
\hline Bowen et $\mathrm{al}^{34}$ & $\begin{array}{l}\text { “... the cost-effectiveness of DES is high for all cohorts investigated, the most favorable } \\
\text { cost-effectiveness being } \$ 223,580 \text { per QALY gained” }\end{array}$ & No \\
\hline Bakhai et al ${ }^{29}$ & $\begin{array}{l}\text { "...treatment with PES led to substantial reductions in the need for repeat } \\
\text { revascularization while increasing } 1 \text {-year costs only modestly" }\end{array}$ & Yes \\
\hline Ekman et $\mathrm{al}^{30}$ & $\begin{array}{l}\text { "Strong case for high risk patients. ...cost revascularization avoided looks attractive for } \\
\text { moderate risk" }\end{array}$ & Yes \\
\hline Ikeda et $\mathrm{al}^{31}$ & $\begin{array}{l}\text { "SES would be a cost-saving option as compared with BMS implantation within the } \\
\text { context of the Japanese healthcare system" }\end{array}$ & Yes \\
\hline
\end{tabular}

Note: $\mathrm{SES}=$ sirolimus-eluting stent, $\mathrm{BMS}=$ bare-metal stent, $\mathrm{DES}=$ drug-eluting stent, $\mathrm{PCI}=$ percutaneous coronary intervention, $\mathrm{QALY}=$ quality-adjusted life-year, US = United States, PES = paclitaxel-eluting stent. 
Several of the study characteristics were interrelated. For example, lower study quality was associated with sponsorship $(p=0.06)$ and with the United States being the country of origin $(p=0.032)$. The United States as country of origin was also correlated with sponsorship $(p=0.038)$.

\section{Interpretation}

Our systematic review of studies evaluating the costeffectiveness of drug-eluting stents demonstrated differences in the conclusions of the I9 identified studies, with $53 \%$ favouring and $47 \%$ not favouring widespread use of these stents. Specific study characteristics were found to be associated with the final study conclusion. Studies of lower quality and those that had direct sponsorship from a manufacturer of a drug-eluting stent were strongly associated with a positive endorsement of widespread use of drug-eluting stents. Also, studies performed with a US cost perspective were more likely than those performed in other countries to favour widespread use.

Sponsorship was inversely associated with the overall quality of these economic studies. Although a study of industry-sponsored RCTs did not find them to be of poorer quality, ${ }^{35}$ RCT quality metrics are much simpler to evaluate than those of economic studies. Moreover, a recent publication of multiple systematic reviews demonstrated the same observation as ours of a relation between sponsorship and study quality. ${ }^{36}$

Cost-effectiveness studies that favoured widespread use of drug-eluting stents were more likely than those not favouring such use to be published early after the introduction of this

Table 3: Relation between covariates and conclusions of costeffectiveness studies regarding widespread use of drug-eluting stents

\begin{tabular}{|c|c|c|c|}
\hline \multirow[b]{2}{*}{ Covariate* $^{*}$} & \multicolumn{2}{|c|}{$\begin{array}{l}\text { Conclusion regarding use of } \\
\text { drug-eluting stents; no. of studies }\end{array}$} & \multirow[b]{2}{*}{$p$ value } \\
\hline & $\begin{array}{c}\text { Favoured } \\
\text { widespread use }\end{array}$ & $\begin{array}{l}\text { Did not favour } \\
\text { widespread use }\end{array}$ & \\
\hline \multicolumn{4}{|l|}{ Quality } \\
\hline High & 1 & 8 & \\
\hline Low & 9 & 1 & $<0.001$ \\
\hline \multicolumn{4}{|l|}{ Sponsorship } \\
\hline Sponsored & 7 & 0 & \\
\hline Not sponsored & 3 & 9 & 0.003 \\
\hline \multicolumn{4}{|l|}{ Country } \\
\hline United States & 5 & 0 & \\
\hline Other & 5 & 9 & 0.032 \\
\hline \multicolumn{4}{|l|}{ Year } \\
\hline$<2005$ & 6 & 2 & \\
\hline$\geq 2005$ & 4 & 7 & 0.17 \\
\hline
\end{tabular}

*Quality = quality according to score from instrument in Appendix 1 (available online at www.cmaj.ca/cgi/content/full/176/2/199/DC1); sponsored = directly sponsored by manufacturer of drug-eluting stent; country = country of analysis; year $=$ year of publication.

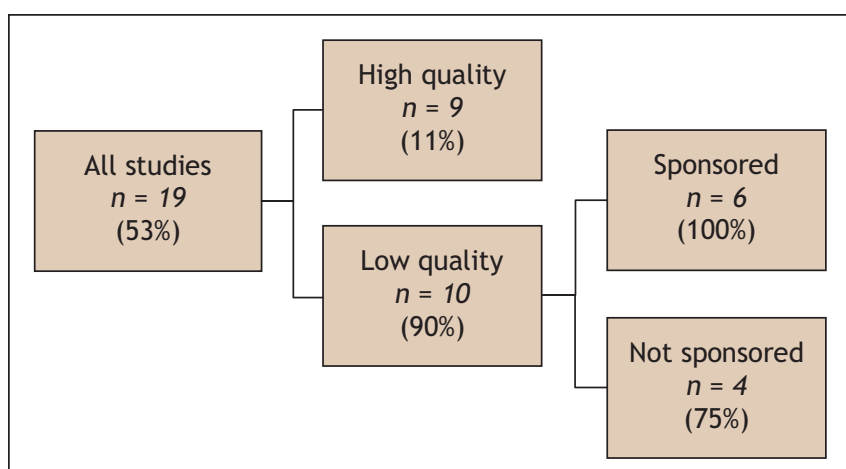

Misclassification error rate $0.11(2 / 19)$; residual mean deviance 0.68 .

Fig. 2: Results of classification and regression tree (CART) analysis showing study characteristics that were predictive of the main outcome measure (study favoured use of drug-eluting stents). Percentages in parentheses indicate the proportion of studies that favoured widespread use. Quality = quality as determined with the use of the instrument in Appendix 1 (available online at www.cmaj.ca/cgi/content/full/176/2/199/DC1); sponsored = study directly sponsored by manufacturer of drug-eluting stent.

technology (Table I), when encouraging results are most essential to advance dissemination and adoption. Compared with the earlier studies, later studies by health technology assessment agencies were in general more extensive, were of higher quality, had no industry sponsorship and argued that widespread use of drug-eluting stents was economically unattractive and that a more focused approach concentrating on high-risk patients was indicated. ${ }^{21,23,24,33,34}$ Because of their later publication date, their appearance in nonclinical journals and their length and complexity, their impact on clinicians' practices may be lower than that of earlier, more enthusiastic articles published in clinical journals. In 2006, there appears to have been a rebuttal with 3 additional articles favouring widespread use. ${ }^{29-31}$ Through their associations both with industry funding and lower quality, our analysis suggests that care should be exercised in the interpretation of these early cost-effectiveness studies.

Finally, our findings suggest that the transferability of cost-effectiveness results from one country to another may be of concern. The difference in study conclusions can perhaps be explained in part by the variation in costs between different geographic locations. In support of this argument, the fact that all of the US studies favoured widespread adoption of drug-eluting stents may, at least in part, be explained by the high revascularization costs in the US health care system that could be substantially reduced with the use of drug-eluting stents. The threshold for accepting an intervention as being cost-effective is also higher in US studies. This suggests that other jurisdictions should carefully examine the conclusions of US cost-effectiveness studies before incorporating them into local decision-making and policy.

Our study has a number of strengths and makes several unique contributions to this burgeoning literature. First, although previous publications ${ }^{35,37}$ have suggested an association between sponsorship and study conclusions, the ana- 
lyzed studies were generally performed before 2000/or, and it was unknown whether the same trends persist currently. Previous studies have also examined multiple interventions, which increases interstudy variability and complicates overall analyses and interpretation. For example, the previous associations between favourable economic recommendations and industry sponsoring observed in a systematic review of 494 cost-effectiveness studies ${ }^{37}$ could be explained, without evoking any suggestion of bias, if industry had selectively decided early in the life span of a technology not to pursue economically unattractive interventions. Our study is the first to examine exclusively one technology, thereby providing a common denominator for evaluation. This minimizes interstudy variability, enhances transparency and facilitates the attribution of study characteristics to outcomes. We were also able to reliably exclude time-varying efficacy measures as an explanation for the different study conclusions, since these have remained relatively stable over the clinical course of this technology. For example, the first clinical efficacy trials ${ }^{2,3}$ showed results similar to those of a later meta-analysis that incorporated several more recent RCTs. ${ }^{7}$ Our outcome measure has also been diligently and transparently recorded (see Table 2 ) and was not encumbered by the use of differing, arbitrary QALY thresholds. The robustness of our conclusions with different quality scales and our use of relative quality comparisons are other strengths. Finally, this is the first study of sponsorship portending to the device industry.

Our study does have some limitations. First, the small sample limits the number of variables that can be independently assessed in a multivariable analysis. This is especially pertinent because several of our study characteristics were significantly correlated. Second, although we used 2 different scales, there is no definitive method on how to evaluate the quality of cost-effectiveness analyses. ${ }^{39-41}$ Moreover, we were unable to completely assess the validity of the input variables for each study. Third, we excluded several studies not published in English, but later work should address this deficiency. Fourth, although our outcome measure - whether studies favoured widespread use of drug-eluting stents may be considered too broad by some, it nevertheless avoids the ambiguities of more intricate measures. None of the original studies in our review considered the clinical and economic consequences of late stent thrombosis with drugeluting stents. Finally, our evaluation of sponsorship was based on reported funding in the original publications and does not include any assessment of indirect or unreported funding or conflicts.

Our systematic review suggests that cost-effectiveness analyses can lead to partisan conclusions, at least regarding the evaluation of drug-eluting stents. Specifically, published studies have reached different conclusions despite the use of standardized measures of efficacy. We provide empirical evidence that lower study quality and direct industry sponsorship were associated with positive conclusions favouring widespread use of drug-eluting stents. Moreover, caution should be exercised in drawing conclusions from early costeffectiveness studies, particularly if funded by industry, and in transferring conclusions from one country to another juris- diction. Readers, journal editors and policy-makers need to be aware of the impact that these study characteristics may have on the conclusions of cost-effectiveness analyses. Vigilance is therefore required when interpreting findings from cost-effectiveness studies of drug-eluting stents, and possibly other cost effectiveness analyses.

This article has been peer reviewed.

From the Department of Medical Technology Assessment (Ligthart, Vlemmix), University Medical Centre Nijmegen, Nijmegen, the Netherlands; the Technology Assessment Unit (Ligthart, Vlemmix, Dendukuri, Brophy), McGill University Health Centre, Montréal, Que.; and the Departments of Epidemiology and Biostatistics (Dendukuri, Brophy) and Medicine (Brophy), McGill University, Montréal, Que.

Competing interests: None declared.

Contributors: James Brophy conceived the study. All of the authors contributed substantially to the design of the study, the acquisition, analysis and interpretation of the data, the drafting of the article and the revising of it critically for important intellectual content. All of the authors gave final approval of the version to be published.

\section{REFERENCES}

I. Ong AT, Serruys PW. Technology insight: an overview of research in drug-eluting stents. Nat Clin Pract Cardiovasc Med 2005;2:647-58.

2. Brophy JM, Belisle P, Joseph L. Evidence for use of coronary stents: a hierarchical Bayesian meta-analysis. Ann Intern Med 2003;138:777-86.

3. Morice MC, Serruys PW, Sousa JE, et al. A randomized comparison of a sirolimuseluting stent with a standard stent for coronary revascularization. $N$ Engl J Med 2002;346:1773-80.

4. Moses JW, Leon MB, Popma JJ, et al. Sirolimus-eluting stents versus standard stents in patients with stenosis in a native coronary artery. N Engl JMed 2003;349:1315-23.

5. Schampaert E, Cohen EA, Schluter M, et al. The Canadian study of the Sirolimuseluting stent in the treatment of patients with long de novo lesions in small native coronary arteries (C-SIRIUS). JAm Coll Cardiol 2004;43:IIIO-5.

6. Schofer J, Schluter M, Gershlick AH, et al. Sirolimus-eluting stents for treatment of patients with long atherosclerotic lesions in small coronary arteries: double-blind, randomized controlled trial (E-SIRIUS). Lancet 2003;362:1093-9.

7. Babapulle MN, Joseph L, Belisle P, et al. A hierarchical Bayesian meta-analysis of randomized clinical trials of drug-related stents. Lancet 2004;364:583-9I.

8. Brophy JM. The dollars and sense of drug-eluting stents. CMAJ 2005;172:36I-2.

9. Ward MR. Cost-benefit of drug-eluting stents; time for a reality check. Heart Lung Circ 2005;I4:74-7.

Io. Feder BJ. J.\& J. deal for stent maker clouded by patent disputes. NY Times 2006 Nov I8. Available http://query.nytimes.com/gst/fullpage.html?sec=health\&res

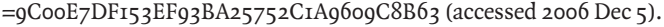

II. Kastrati A, Dibra A, Eberle S, et al. Sirolimus-eluting stents vs Paclitaxel-eluting stents in patients with coronary artery disease. JAMA 2005;294:819-25.

I2. Neumann PJ, Stone PW, Chapman RH, et al. The quality of reporting in published cost-utility analyses, I976-I997. Ann Intern Med 2000;132:964-72.

I3. Chiou C, Hay J, Wallace JF, et al. Development and validation of a grading system for the quality of cost-effectiveness studies. Med Care 2003;4I:32-44.

I4. Spiegel BMR, Targownik LE, Kanwal F, et al. The quality of published health economic analyses in digestive diseases: a systematic review and quantitative appraisal. Gastroenterology 2004;I27:403-II.

I5. Breiman L, Friedman JH, Olshen RA, et al. Classification and regression trees [Wadsworth statistics/probability series]. Boca Raton (FL): Chapman \& Hall/CRC; I984.

I6. Crichton NJ, Hinde JP, Marchini J. Models for diagnosing chest pain: Is CART helpful? Stat Med i997; I6(7): 717-27.

17. Greenberg D, Cohen DJ. Examining the economic impact of restenosis: implications for the cost-effectiveness of an antiproliferative stent. Z Kardiol 2002;91:137-43.

I8. Galanaud JP, Delavennat J, Durand-Zaleski I. A break-even price calculation for the use of sirolimus-eluting stents in angioplasty. Clin Ther 2003;25:1007-I6.

I9. Greenberg D, Bakhai A, Cohen DJ. Can we afford to eliminate restenosis? Can we afford not to? J Am Coll Cardiol 2004;43:513-8.

20. Cohen DJ, Bakhai A, Shi C, et al. Cost-effectiveness of sirolimus-eluting stents for treatment of complex coronary stenoses: results from the Sirolimus-Eluting Balloon Expandable Stent in the Treatment of Patients With De Novo Native Coronary Artery Lesions (SIRIUS) trial. Circulation 2004;IIO:508-I4.

2I. Hill R, Bagust A, Bakhai A, et al. Coronary artery stents: a rapid systematic review and economic evaluation. Health Technol Assess 2004;8: iii-iv, I-242.

22. Tarricone $\mathrm{R}$, Marchetti $\mathrm{M}$, Lamotte $\mathrm{M}$, et al. What reimbursement for coronary revascularization with drug-eluting stents? Eur J Health Econ 2004;5:309-I6. 
23. Brophy JM, Erickson LJ. Cost-effectiveness of drug-eluting coronary stents in Quebec, Canada. Int J Technol Assess Health Care 2005;2I:326-33.

24. Lord SJ, Howard K, Allen F, et al. A systematic review and ecomomic analysis of drug-eluting coronary stents available in Australia. Med J Aust 2005;183:464-7I.

25. Bagust A, Grayson AD, Palmer ND, et al. Cost-effectiveness of drug-eluting coronary artery stenting in a UK setting: cost-utility study. Heart 2006; 92:68-74.

26. Van Hout BA, Serruys PW, Lemos PA, et al. One year cost effectiveness ofsirolimus eluting stents compared with bare metal stents in the treatment of single native de novo coronary lesions: an analysis from the RAVEL trial. Heart 2005;91:507-I2.

27. Shrive FM, Manns BJ, Galbraith PD, et al. APPROACH Investigators. Economic evaluation of sirolimus-eluting stents. CMAJ 2005;I72:345-5I.

28. Kaiser C, Brunner-La Rocca P, Buser PT, et al. Incremental cost-effectiveness of drug-eluting stents compared with a third-generation bare-metal stent in a realworld setting: randomised Basel Stent Kosten Effectivitats Trial (BASKET). Lancet 2005; 366: 92I-9.

29. Bakhai A, Stone GW, Mahoney E, et al. Cost effectiveness of paclitaxel-eluting stents for patients undergoing percutaneous coronary revascularization: results from the TAXUS-IV Trial. J Am Coll Cardiol 2006;48:253-6I.

30. Ekman M, Sjogren I, James S. Cost-effectiveness of the Taxus paclitaxel-eluting stent in the Swedish healthcare system. Scand Cardiovasc J. 2006;40:17-24

3I. Ikeda S, Kobayashi M: Economic evaluation of drug-eluting stents in Japan. Keio J Med 2006;55:15-22

32. Ruffy R, Kaden RJ. Projected health and economic benefits of the use of sirolimuseluting coronary stents. Adv stud med 2003; 3(6D): 602-II.

33. Mittmann N, Brown A, Seung SJ, et al. Drug eluting stents: an economic evaluation. (Technology overview no. I5). Ottawa: Canadian Coordinating Office for Health Technology Assessment; 2005. Available: www.cadth.ca/media/pdf/372 _drug_eluting_stents_ov_e.pdf (accessed 2006 Nov 8).

34. Bowen J, Hopkins R, He Y, et al. Systematic review and cost-effectiveness analysis of drug eluting stents compared to bare metal stents for percutaneous coronary interventions in Ontario. Interim Report for the Ontario Ministry of Health and Long-term Care. Report No.: HTA002-0512. Hamilton (ON): Program for Assessment of Technology in Health, McMaster University; 2005. p.I70. Available: www .path-hta.ca/DESreport.pdf (accessed 2006 Nov 8).

35. Lexchin J, Bero LA, Djulbegovic B, et al. Pharmaceutical industry sponsorship and research outcome and quality: systematic review. BMJ 2003;326:Ir67-70.

36. Biondi-Zoccai GGL, Lotrionte M, Abbate A, et al. Compliance with QUORUM and quality of reporting of overlapping meta-analyses on the role of acetylcysteine in the prevention of contrast associated nephropathy: case study. BMJ 2006;332:202-9.

37. Stelfox HT, Chua G, O'Rourke K, et al. Conflict of interest in the debate over calcium-channel antagonists. N Engl J Med I998;338:I0I-6.

38. Bell CM, Urbach DR, Ray JG, et al. Bias in published cost effectiveness studies: systematic review. BMJ 2006;332:699-703.

39. Taylor RS, Drummond MF, Salkeld G, et al. Inclusion of cost effectiveness in licensing requirements of new drugs: the fourth hurdle. BMJ 2004;329:972-5.

40. Drummond MF, Jefferson TO. Guidelines for authors and peer reviewers of economic submissions to the BMJ. BMJ I996;313:275-83.

4I. Reed SD, Anstrom KJ, Bakhai A, et al. Conducting economic evaluations alongside multinational clinical trials: toward a research consensus. Am Heart J 2005; I49: 434-43.

Correspondence to: Dr. James M. Brophy, Divisions of Cardiology and Clinical Epidemiology, Rm. R4.I2, McGill University Health Centre, Royal Victoria Hospital, 687 Pine Ave. W, Montréal QC H3A IAI; james.brophy@mcgill.ca

\section{IMPACT}

$C M A J$ is a leading international general medical journal as ranked by Thomson ISI. 2005 impact factor, 7.4. 